\title{
Routine Use of a Thiol-Detection Test in Every Wellness Examination Increased Practice Dental Revenues and Enhanced Client Compliance with Dental Recommendations in Veterinary General Practice Clinics
}

\author{
Gary Goldstein ${ }^{1}$, Angela Chapman ${ }^{2}$, Leslie Herzog ${ }^{2}$ and George David McClure ${ }^{2 *}$ \\ ${ }^{1}$ College of Veterinary Medicine, University of Minnesota; Current address: Best Friends Veterinary Group, 1971762 Avenue South, Kent, WA, 98032, USA \\ ${ }^{2} P D x$ BioTech, 315 S Broadway, Lexington, KY 40508, USA
}

"Corresponding author: George David McClure, PDx BioTech, 315 S Broadway, Lexington, KY 40508, USA, Tel: 18593889445; E-mail: dmcclure@periodx.com

Rec date: Mar 14, 2016; Acc date: Mar 29, 2016; Pub date: Mar 31, 2016

Copyright: $@ 2016$ Goldstein G, et al. This is an open-access article distributed under the terms of the Creative Commons Attribution License, which permits unrestricted use, distribution, and reproduction in any medium, provided the original author and source are credited.

\begin{abstract}
Routine use of a thiol-detection test in every wellness examination increased practice dental revenues and enhanced client compliance with dental recommendations in a geographically diverse cohort of veterinary generalpractice clinics. The number of dental procedures performed and home-care units dispensed increased, as did revenues.
\end{abstract}

Keywords Periodontal disease; Dog; Thiol-detection test; Client communication; Early detection; Prevention; Compliance

\section{Introduction}

Periodontal disease is the most common infectious disease in adult dogs [1-3]. It affects almost all dogs and cats over two years of age and is also frequently observed in younger dogs when a full-mouth anesthetized examination, necessary for proper diagnosis of periodontal disease, is performed [4]. Periodontal disease is responsible for the destruction of the periodontium, the supporting structures of the teeth. Periodontal disease has been linked to liver, kidney, and heart pathology [5]. Periodontal disease can be prevented with good oral hygiene and regular professional veterinary dental care. Once established, it is an incurable disease process that is progressive but can be controlled or maintained with proper veterinary treatment and good oral hygiene [1,6]. Clients are becoming more aware of dental disease in dogs and cats because of improved client communication and a growing emphasis on wellness examinations and preventive medicine [7].

When proper clinical diagnostics including a thiol-detection test are routinely utilized, periodontal disease can be detected early, because the concentration of thiols sampled from oral fluids is directly related to the presence and severity of active periodontal disease [8-12]. In dogs, this direct relationship between oral fluid thiol levels and periodontal disease activity has been shown to be particularly strong $[4,12]$.

Because periodontal disease cannot be detected visually until it is in its most advanced stages, pet owners are typically unaware of its presence and significance unless their veterinarian educates them on the importance and seriousness of progressive periodontal disease. For this reason, the veterinary team must be proactive in identifying opportunities for communicating to clients the critical importance of the early detection of periodontal disease, and for educating clients about its treatment and management. In this study, a set of geographically diverse clinics consistently utilized a thiol-detection test in every wellness examination and recorded the impact of its consistent utilization on client compliance and practice revenues.

\section{Materials and Methods}

Veterinary general practices in geographically diverse areas of the United States were recruited and were accepted for participation in the study if they met the following inclusion criteria: the practice had not previously used a thiol-detection test; the practice performed general anesthetized professional dental cleanings and had a variety and inventory of veterinary home-care products available; the practice had adequate dental equipment and instrumentation including dental high speed and ultrasonic scaling capabilities, along with dental radiology and appropriate periodontal and extraction instrumentation; the practice could provide data on number of units of professional dental cleanings, veterinary dental home-care products and other dentalrelated products and services, and on revenues derived from them. The recruited practices meeting the inclusion criteria were four veterinary hospitals in non-contiguous regions of the United States, on the East Coast and the West Coast and in the Central region of the country.

The study period was three months long. Data gathered from that three-month period were compared to data from a three-month period exactly one year prior to that period.

In every wellness examination during the study period, the visual awake examination was performed as described previously $[7,12]$. In every wellness examination, a thiol-detection test [OraStrip ${ }^{\circ}$ QuickCheck Canine, PDx BioTech, Lexington, KY, US] was also administered by the attending veterinarian or a veterinary technician. The test was read and interpreted, and the test result was shown to the client. Discussion of the test result was routinely incorporated into the veterinarian's conversation with the client in the examination room about dental health and the veterinarian's recommendations concerning dental procedures and home-care products. Client compliance with veterinarian dental recommendations was recorded; there were no historical data from the previous year on client compliance, so no year-over-year compliance comparisons were made. 
Citation: Goldstein G, Chapman A, Herzog L, McClure GD (2016) Routine Use of a Thiol-Detection Test in Every Wellness Examination Increased Practice Dental Revenues and Enhanced Client Compliance with Dental Recommendations in Veterinary General Practice Clinics. J Veterinar Sci Techno 7: 312. doi:10.4172/2157-7579.1000312

Page 2 of 4

Each patient received contemporary standard-of-care treatment once client consent was obtained.

Data for each patient were recorded in a standard Case Report Form. Data for each veterinary practice were compiled and analyzed. Data from the four practices were aggregated in order to preserve individual practice information confidentiality.

\section{Results}

The results of the study for major categories of dental and dentalrelated procedures are presented in Table 1.

\begin{tabular}{|l|l|l|l|}
\hline & $\begin{array}{l}\text { Control period (same months in previous year; } \\
\text { no thiol-detection test) }\end{array}$ & $\begin{array}{l}\text { Study period (thiol-detection test used in every } \\
\text { wellness examination }\end{array}$ & $\begin{array}{l}\text { Difference between study period and } \\
\text { control period }\end{array}$ \\
\hline \multicolumn{2}{|l|}{ Professional dental cleaning under anesthesia } & \multicolumn{2}{l|}{} \\
\hline Units & 160 & 246 & $54 \%$ increase \\
\hline Revenue & $\$ 36,423.64$ & $\$ 61,202.45$ & $68 \%$ increase \\
\hline Dental radiology & 94 & 219 & $133 \%$ increase \\
\hline Units & 94 & $\$ 16,697.25$ & $141 \%$ increase \\
\hline Revenue & $\$ 6,925.10$ & & \\
\hline
\end{tabular}

Table 1: Dental and dental-related procedures.

The results of the study for major categories of dental home-care products are presented in Table 2.

\begin{tabular}{|c|c|c|c|}
\hline & $\begin{array}{l}\text { Control period (same months in previous } \\
\text { year; no thiol-detection test) }\end{array}$ & $\begin{array}{l}\text { Study period (thiol-detection test used in every } \\
\text { wellness examination }\end{array}$ & $\begin{array}{l}\text { Difference between study period and } \\
\text { control period }\end{array}$ \\
\hline \multicolumn{4}{|c|}{ Toothbrush/toothpaste } \\
\hline Units & 20 & 115 & $475 \%$ increase \\
\hline Revenue & $\$ 167.64$ & $\$ 715.86$ & $327 \%$ increase \\
\hline \multicolumn{4}{|c|}{ Oral rinse/gel } \\
\hline Units & 1 & 22 & $2100 \%$ increase \\
\hline Revenue & $\$ 20.68$ & $\$ 270.79$ & $1209 \%$ increase \\
\hline \multicolumn{4}{|c|}{ Special dental food/chews/treats } \\
\hline Units & 34 & 75 & $121 \%$ increase \\
\hline Revenue & $\$ 549.43$ & $\$ 949.00$ & $73 \%$ increase \\
\hline
\end{tabular}

Table 2: Dental home-care products.

The results of the study for various overall practice categories are presented in Table 3.

\begin{tabular}{|l|l|l|l|}
\hline & $\begin{array}{l}\text { Control period (same months in previous } \\
\text { year; no thiol-detection test) }\end{array}$ & $\begin{array}{l}\text { Study period (thiol-detection } \\
\text { test used in every wellness } \\
\text { examination }\end{array}$ \\
\hline and control period \\
Number of canine wellness visits & 774 & 678 & $12 \%$ decrease \\
\hline $\begin{array}{l}\text { Revenue from all dental procedures and } \\
\text { products }\end{array}$ & $\$ 67,178.00$ & $\$ 116,065.20$ & $73 \%$ increase \\
\hline $\begin{array}{l}\text { Revenue from all dental home-care } \\
\text { products }\end{array}$ & $\$ 2,161.77$ & $\$ 3,454.64$ & $60 \%$ increase \\
\hline
\end{tabular}

Table 3: Comprehensive practice categories. 
Citation: Goldstein G, Chapman A, Herzog L, McClure GD (2016) Routine Use of a Thiol-Detection Test in Every Wellness Examination Increased Practice Dental Revenues and Enhanced Client Compliance with Dental Recommendations in Veterinary General Practice Clinics. J Veterinar Sci Techno 7: 312. doi:10.4172/2157-7579.1000312

Page 3 of 4

The results of the study for client compliance with veterinarian dental recommendations are presented in Table 4.

\begin{tabular}{|l|l|}
\hline & Compliance rate (\% of veterinarian dental recommendations that clients complied with) \\
\hline Professional dental cleaning under anesthesia & $54 \%$ \\
\hline Dental radiology & $57 \%$ \\
\hline Dental home-care products & $80 \%$ \\
\hline
\end{tabular}

Table 4: Client compliance with veterinarian dental recommendations.

\section{Discussion}

This study shows the importance of a thiol-detection test in facilitating discussion with the pet owner concerning dental health and its relationship to the overall well-being of the pet. Substantial increases in all categories of dental procedures (Table 1), including professional dental cleanings, dental radiology, and dental products (Table 2), were observed in the study period, when the thiol-detection test was utilized in every wellness examination, compared to the control period, when the thiol-detection test was not utilized. Practice dental revenues substantially increased when the thiol-detection test was routinely utilized (Table 3 ). Client compliance with veterinarian recommendations was high (Table 4) during the study period. This high rate of compliance was based on routine utilization of the thioldetection test, providing the veterinarian with an objective basis for the recommendation that was presented to the client.

These results are all the more impressive since the four study practices actually conducted fewer wellness examinations in the study period than in the control period (Table 3). Revenues for all dental procedures nevertheless increased substantially, as did revenues from all dental home-care products.

The basis for the impressive increases in revenue includes the high rates of compliance with veterinarian dental recommendations (Table 4) when there is routine use of a thiol-detection test in every wellness examination. Routine use of the thiol-detection test improved awareness of the importance of the early detection of periodontal disease and facilitated more productive discussions with clients.

The effectiveness of the thiol-detection test is consistent with its inclusion in the current American Animal Hospital Association Guidelines as standard-of-care [7]. This effectiveness has also been demonstrated in other controlled clinical trials in which the thioldetection test result was shown to be directly related to the presence and severity of active periodontal infection and in which the thioldetection test disclosed underlying active periodontal disease not seen in the visual awake examination $[4,12]$.

Because periodontal disease is common, chronic and progressive, it must be addressed throughout the pet's life, since dogs as young as one year of age can experience alveolar bone loss [4]. Despite this clear necessity, veterinarians tend to underestimate the presence and severity of periodontal disease and its harmful effects on the pet's health [13]. This unfortunately translates into inadequate utilization of veterinary dentistry, especially in young dogs. This underutilization is due to unclear recommendations to clients, resulting in low rates of compliance with veterinarian recommendations for dental procedures and home-care products [14].
Veterinarian recommendations are more likely to be followed when they are clear and unambiguous and when they are grounded in a firm, objective basis [15]. In this study, the thiol-detection test provided a firm, objective basis for veterinarian recommendations of dental procedures, including professional dental cleanings and radiography, and home-care products. Routine use of the thiol-detection test therefore resulted in clear and unambiguous recommendations and high rates of compliance. This in turn resulted in substantially increased practice dental revenues.

\section{Conclusion}

Routine use of a thiol-detection test in every wellness examination resulted in increased utilization of dental procedures, including professional dental cleanings, radiology, and increased sales of dental home-care products. This was the result of the thiol-detection test providing an objective basis for veterinarian recommendations to address periodontal disease proactively, resulting in high rates of client compliance and increased practice revenues. It has previously been established that a thiol-detection test is effective in detecting active periodontal disease $[4,12]$. The present study further demonstrates the significant economic and clinical benefits of routine use of a thioldetection test in every wellness examination.

\section{References}

1. Wiggs RB, Lobprise HB (1997) Veterinary dentistry-principles and practice. Philadelphia: Lippincott-Raven Publishers, pp: 186-231.

2. Harvey CE (1998) Periodontal disease in dogs. Etiopathogenesis, prevalence, and significance. Vet Clin North Am Small Anim Pract 28: 1111-1128.

3. DuPont GA (1998) Prevention of periodontal disease. Vet Clin North Am Small Anim Pract 28: 1129-1145.

4. Queck KE (2016) Oral-fluid thiol-detection test identifies underlying active periodontal disease not detected by the visual awake examination. J Am Anim Hosp Assoc (In press).

5. DeBowes LJ, Mosier D, Logan E, Harvey CE, Lowry S, et al. (1996) Association of periodontal disease and histologic lesions in multiple organs from 45 dogs. J Vet Dent 13: 57-60.

6. Niemec BA (2008) Periodontal disease. Top Companion Anim Med 23: 72-80.

7. Holmstrom SE, Bellows J, Juriga S, Knutson K, Niemiec BA, et al. (2013) 2013 AAHA dental care guidelines for dogs and cats. J Am Anim Hosp Assoc 49: 75-82.

8. Persson S (1992) Hydrogen sulfide and methyl mercaptan in periodontal pockets. Oral Microbiol Immunol 7: 378-379.

9. Torresyap G, Haffajee AD, Uzel NG, Socransky SS (2003) Relationship between periodontal pocket sulfide levels and subgingival species. J Clin Periodontol 30: 1003-1010. 
Citation: Goldstein G, Chapman A, Herzog L, McClure GD (2016) Routine Use of a Thiol-Detection Test in Every Wellness Examination Increased Practice Dental Revenues and Enhanced Client Compliance with Dental Recommendations in Veterinary General Practice Clinics. J Veterinar Sci Techno 7: 312. doi:10.4172/2157-7579.1000312

Page 4 of 4

10. Hardan S, Khocht A, Suzuki J (2011) A clinical investigation of the association of a biochemical chairside assay and periodontal parameters. J Clin Dent 22: 36-39.

11. Khocht A, Seyedain M, Hardan S, Gaughan J, Suzuki JB (2013) Salivary thiol levels and periodontal parameters assessed with a chromogenic strip. Gen Dent 61: 50-54.

12. Manfra Marretta S, Leesman M, Burgess-Cassler A, McClure GD Jr, Buelow M, et al. (2012) Pilot evaluation of a novel test strip for the assessment of dissolved thiol levels, as an indicator of canine gingival health and periodontal status. Can Vet J 53: 1260-1265.
13. Lund EM, Armstrong PJ, Kirk AC (1999) Health status and population characteristics of dogs and cats examined at private veterinary practices in the United States. J Am Vet Med Assoc 214: 1336-1341.

14. Kanji N, Coe JB, Adams CL, Shaw JR (2012) Effect of veterinarian-clientpatient interactions on client adherence to dentistry and surgery recommendations in companion-animal practice. J Am Vet Med Assoc 240: 427-436.

15. Rochette J (2011) Avoiding the "no". Can Vet J 52: 1361-1362. 